\title{
Efficacy of path-oriented psychological self- help interventions to improve mental health of empty-nest older adults in the Community of China
}

\author{
Li-Na Wang ${ }^{1}$, Hong Tao ${ }^{2}$, Mi Wang ${ }^{3}$, Hong-Wei Yu' ${ }^{1}$, Hong Su ${ }^{4}$ and Bei Wu ${ }^{5^{*}}$
}

\begin{abstract}
Background: China has the world's largest aging population and the number of empty-nest older adults is on the rise. In comparison to the aging population in general, empty-nest older adults have a lower level of subjective well-being and poorer mental health status due to a lack of emotional support from their children. The aim of this study is to conduct an empirical study to evaluate the efficacy of the 'Path-oriented Psychological Self-help Intervention' (P-oPSI) led by nurses on the mental health of empty-nest older adults in the community, to provide a scientific foundation for improving their quality of life.

Methods: A Quasi-Experimental controlled intervention study was conducted from 2015 to 2017.

A total of 76 empty-nest older adults from 2 districts were recruited using a convenience sampling and assigned to 2 groups based on their residential communities in the city of Chifeng in the Inner Mongolia Autonomous Region, China. The wait list control group participated in a mental health lecture to gain knowledge and learn techniques of mental health promotion. The intervention group additionally received 1 month of training in a nurse-led 'P-oPSI' for a month. Both groups were followed-up for 3 months. Mental health status, coping styles, and psychological self-help ability of the participating empty nest older adults were assessed at the baseline, 1 month, and 3-months follow up, respectively. Two-way analysis of variance and a simple effect test were used to analyse the differences of the two groups.
\end{abstract}

Results: The P-oPSI yielded a greater benefit for the mental health status, coping styles, and psychological self-help ability of the participants in the intervention group. Combined with a simple effect test, the scores of the mental health status, positive coping style, and psychological self-help ability of those in the intervention group significantly increased at 1 month after the baseline $(F$ mental health status $=7.59, F$ positive coping style $=7.24, F$ psychological self-help ability $=7.07)$; and the sustainable effect of this program lasted for 3 months after the intervention ( $F$ mental health status $=13.24, F$ positive coping style $=10.42, F$ psychological self-help ability $=10.45$ ), which reached statistical significance $(P<0.01)$.

Conclusions: The P-oPSI program significantly improved the level of mental health of empty-nest older adults in China. This intervention provides a new approach of self-management to improve mental health of older adults in community settings.

Trial registration: chictr.org.cn: ChiCTR1900025552. Retrospectively registered 1 September 2019.

Keywords: Chinese empty-nest older adults, Mental health, Self-help, Structural equation model

\footnotetext{
*Correspondence: bei.wu@nyu.edu

${ }^{5}$ Rory Meyers College of Nursing, New York University, 433 First Avenue, New

York, NY 10010, USA

Full list of author information is available at the end of the article
}

(c) The Author(s). 2019 Open Access This article is distributed under the terms of the Creative Commons Attribution 4.0 International License (http://creativecommons.org/licenses/by/4.0/), which permits unrestricted use, distribution, and reproduction in any medium, provided you give appropriate credit to the original author(s) and the source, provide a link to the Creative Commons license, and indicate if changes were made. The Creative Commons Public Domain Dedication waiver (http://creativecommons.org/publicdomain/zero/1.0/) applies to the data made available in this article, unless otherwise stated. 


\section{Background}

According to the National Bureau of Statistics of the People's Republic of China, there were 241 million people older than 60 years, making up $17.3 \%$ of its total population in 2018. Accompanied with the rapid increase of aging population in China, many older people enter the phase of "empty nest". A large body of literature describes the period in the family lifecycle when children leave the parental home, often referred to as the empty nest phase [1-3]. These older people either live alone (empty-nest singles) or with a spouse (empty-nest couples) [4]. As a result of the prolongation of average life expectancy, the declining fertility rate, population migration, and the trend of young people to live independently after marriage, the phenomenon of empty nest has become a rapidly rising trend among the older adults in the past decade in China. One national report shows that there were 100 million empty nest older adults age 60 and older in 2013, accounting for about $50 \%$ of the total aging population in China [5]. It is estimated that the proportion of empty nest households will reach $90 \%$ by $2030[6]$. Empty nest is becoming a main family structure in China.

In a traditional Chinese family, when parents can no longer take care of themselves, they can live with their children and receive assistance [7]. Currently, the disintegration of the extended family, e.g., after their adult children live independently after marriage or begin to work and live elsewhere, means that many grown-up children are no longer available to help older adults when required. Alongside physical inconveniences or irreversible declines in functional capacity that come with aging, empty nest older adults are more likely to develop empty-nest syndrome, triggering negative emotions and psychological problems such as such as absentmindedness, loneliness, depression, anxiety, pessimism, and others, which are mainly caused by the lack of affection and emotional support from their children for an extended period of time [8]. A recent meta-analysis found that the empty nest parents had higher levels of mental health problems compared to their non-empty nest counterparts [2].

However, because the current social pension system cannot meet the needs of older adults, and the function of family system is weakened by the departure of children, Chinese empty nest older adults suffer from more serious mental disorders than before [4, 9]. A metaanalysis showed that depression affects $40.4 \%$ of the empty nest older adults in China (95\% CI 28.6 to $52.2 \%$ ) [10], which is significantly higher than that for nonempty-nest older adults [11]. It is estimated that approximately $43.6 \%$ of empty-nest older adults have experienced moderate loneliness [12]. Loneliness and depression have a deleterious effect on empty-nest older adults' mental and physical health. The evidence indicates that both loneliness and depressive symptoms are associated with a higher risk of hypertension, vascular stiffness, metabolic syndrome, suicidal ideation and dementia [13]. Loneliness also increased morbidity and mortality when older people also suffer from physical ailments [14]. These mental health disorders often generate stigma and self-grief, and reduce their quality of life [15]. Therefore, psychological problems of the empty-nest older adults become a critical issue in China.

Currently, a large body of literature provides evidence for the efficacy of each of these approaches in maintaining mental health of empty-nest older adults, including psychoeducation, supportive psychotherapy and dredging psychotherapy, cognitive behavioural therapy, reminiscence therapy, music therapy and so forth [16-18]. A recent stream of psychological interventions for older adults has begun to focus on integrated psychological interventions [19]. Integrated psychological interventions combine some of these unidirectional approaches. Many studies have provided evidences for the effectiveness of this approach [20, 21]. However, apart from the increased cost of human resources and time, some authors also have questioned the generalizability of this approach with a standardized manual to individuals, due to a lack of tailoring to individual's needs and personal characteristics [22-24]. In fact, to some extent, the mental function of an individual may also develop in old age under the synergistic influence of many factors [25]. If an individual has an active role in the self-management of their mental health, it could improve their mental health by actively adjusting their behaviour. Notably, empty-nest older adults in China have poorer self-management in improving their mental health [4]. Therefore, there are two problems to be explored in the practice of mental health promotion for empty-nest older adults in China: First, how can an integrated intervention strategy leverage the advantages of various approaches and focuses on a person-centred approach? Second, as positive psychological capital, can psychological self-help ability be integrated into the complete psychological intervention system?

Based on our previous work in developing the EmptyNest Older Adults Mental Health Mediation Model using a Structural Equation Modelling (SEM) method [26], our research team focused on three main factors that affect mental health- personality traits, coping styles and psychological self-help ability, and elucidated the path relationships between the three psychological variables by SEM. Hence, according to the various path relationships between three psychological variables and a tailored integrated intervention strategy, we developed a person-centred self-help mental health promotion program, titled "Path-oriented Psychological Self-help Intervention (P-oPSI)." The aim of this study was to conduct 
an empirical study to evaluate the efficacy of P-oPSI led by nurses on the mental health of empty-nest older adults in the community.

We hypothesized that empty-nest older adults who participated in the P-oPSI would have a better performance on mental health status, positive coping style and psychological self-help ability than the wait list control group. We further hypothesized that there were differences in these outcomes between a tailored integrated psychological intervention and group-based mental health education.

\section{Methods}

\section{Study design and participants}

This quasi-experimental study was conducted in Songshan district, located in the city of Chifeng in the Inner Mongolia, China. Songshan district encompasses 7 subdistricts and 48 residential communities. Seventy-six consecutive participants were prospectively divided by convenience sampling into 2 groups. Participants were enrolled into the study at selected 2 of the subdistricts and were measured between July 2015 to March 2017.

The inclusion criteria included: (1) Age 60 and over with urban registration; (2) lived in a home with their children absent; (3) have substandard level of mental health, i.e., scored lower than 163 (transformed by weighting) on a mental health assessment by The Chinese Mental Health Scale; (4) was capable of communicating with the research staff; and (5) was willing to participate in this study. Exclusions included persons with disturbances in consciousness, disorientation, severe physical illness (e.g., severe cardiovascular and cerebrovascular diseases, cancer) or had formal psychotherapy within the past 10 years, that would affect the assessment of the study outcomes.

\section{Sample size}

Based on our pilot study, there was a large effect (Cohen's d $=2.134$, effect size $=0.729$ ) on affected mental health status, assessed by the Chinese Mental Health Scale. Cohen's d effect sizes were calculated for between-group differences of means of the mental health status using an independent-groups pre-test and posttest design (IGPP) [27]. With $\alpha$ set at 0.05 and $\beta$ (power) at 0.95 , the power analysis indicated that 33 participants were required for each group to detect a large effect $(N=66)$. Considering the expected attrition, the decision was made to oversample. Finally, the sample size was 76 (38 cases from the intervention group and the wait list control group, respectively), which was calculated by the $15 \%$ rate of lost follow up.

\section{Sampling and recruitment method}

In this study, multi-stage sampling was used to extract the samples. At stage 1, two subdistricts were randomly selected from the seven subdistricts. These two subdistricts had a similar level of socioeconomic status with the other five subdistricts: annual income per capita: 4479.4 vs. 4454.1 dollars. The proportion of aging population was also similar: 16.32 and $15.30 \%$. At stage 2, one residential community was randomly selected from the seven communities within each of these two subdistricts individually; one community was randomly assigned as a treatment group and one was assigned as a wait list control group. At stage 3, a convenience sampling method was used to recruit participants from these two communities. We distributed recruitment leaflets at community activity centres and healthcare centres, and introduced this study to older adults via in-person meetings at community events. Participants who were interested in the study were instructed to call and arrange a screening appointment. Potential participants who wished to participate and met the inclusion/exclusion criteria through screening were consented and enrolled in the study.

\section{Ethical considerations}

This study protocol was reviewed by the Chifeng University's Institutional Review Board, Clinical Trial Committee in addition to the University Medical Ethics Committee. This study was conducted in accordance with the ethical principles of the Declaration of Helsinki. All empty-nest older adults who met the study's inclusion and exclusion criteria were informed of the study's objectives, procedures, psychological benefits and potential risks. Oral and written consent was obtained from the participants, and all participant information was kept strictly confidential.

\section{Intervention}

\section{Wait list control group}

The participants in wait list control group attended a mental health lecture conducted by the researchers to learn the knowledge and techniques of mental health promotion, and were informed that they would receive the intervention described above after the follow-up assessment.

\section{Intervention group}

In addition to the same mental health lecture given to the wait list control group, the participants of the intervention group received the P-oPSI, i.e., Path-oriented Psychological Self-help Intervention (P-oPSI). The specific steps are as follows:

\section{(1) Select the Optimal Intervention Path}

Six possible impact paths were identified based on the Empty-Nest Older Adults Mental Health Mediation Model using SEM method, which was constructed by our research team (Fig. 1) [26], including: (1) extroversion $\rightarrow$ 


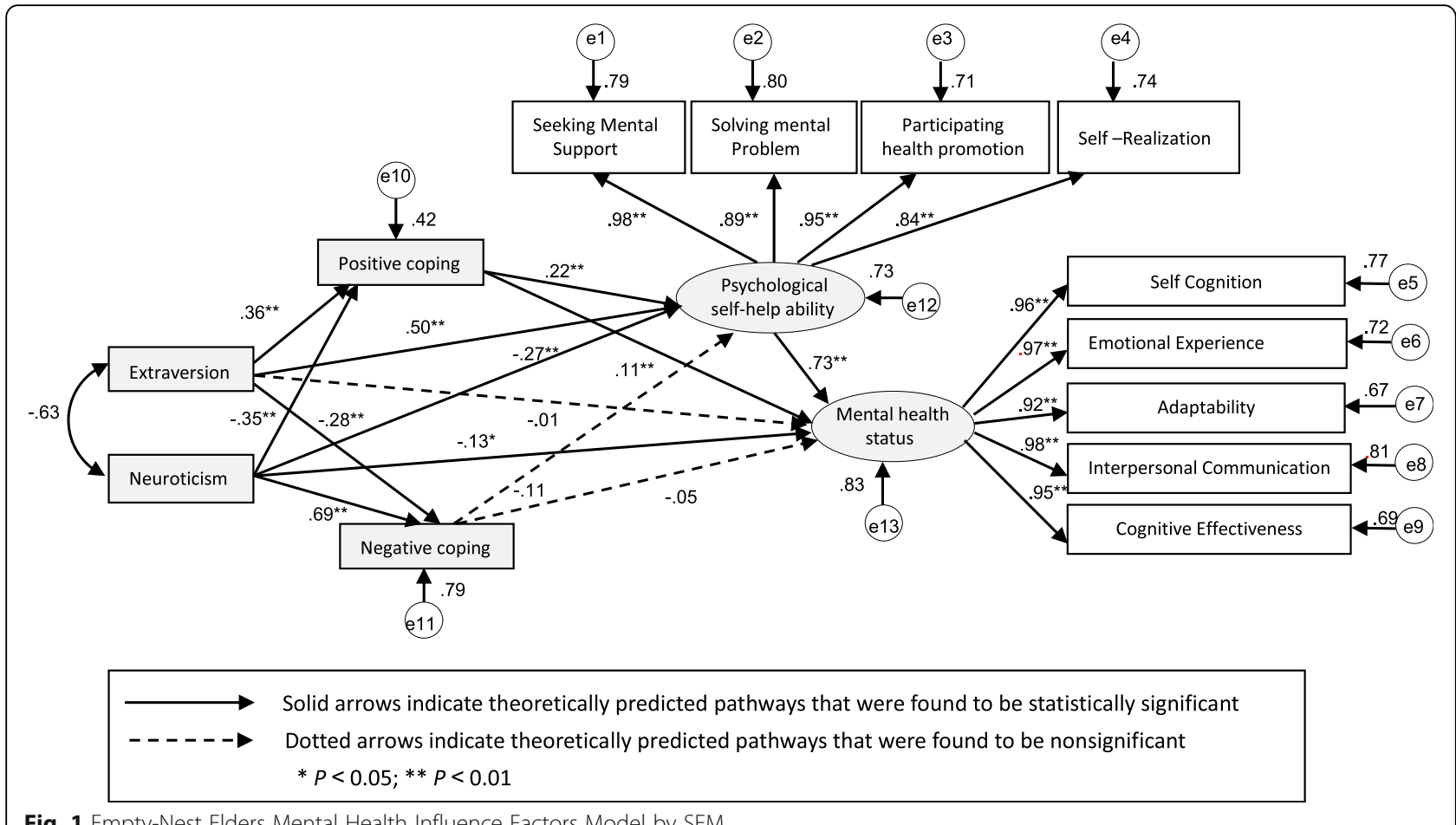

Fig. 1 Empty-Nest Elders Mental Health Influence Factors Model by SEM

positive coping style $\rightarrow$ level of mental health; (2) extroversion $\rightarrow$ positive coping style $\rightarrow$ psychological selfhelp ability $\rightarrow$ level of mental health; (3) extroversion $\rightarrow$ psychological self-help ability $\rightarrow$ level of mental health; (4) neuroticism $\rightarrow$ positive coping style $\rightarrow$ level of mental health; (5) neuroticism $\rightarrow$ positive coping style $\rightarrow$ psychological self-help ability $\rightarrow$ level of mental health; (6) neuroticism $\rightarrow$ psychological self-help ability $\rightarrow$ level of mental health.

According to the psychological characteristics of the assessment results, the researchers ascertained individual-related psychological problems and, accordingly, selected the optimal psychological intervention path and objectives of intervention for the participant. At the same time, the researchers used mediating variables (i.e., positive coping style or/and psychological selfhelp ability) to test the mediating effect to ensure that the psychological variables or characteristics that were dynamically changing could be evaluated timely and intervened promptly for each participant.

\section{(2) Develop Self-help Manual}

Based on the possible intervention paths and the theory and technology of existing psychological interventions, the researchers developed a P-oPSI manual to help guide participants to use this manual (Table 1).

\section{(3) Implement Self-care Psychological Intervention}

Referring to the P-oPSI manual, empty-nest older adults practised a set of simple psychological self-care activities that match her or his optimal intervention paths at home or community activity centre for 1 month. The researchers re-evaluated the mental health outcomes of the participants through face-to-face or telephone interviews every week, and re-adjusted the participant's optimal psychological intervention path and corresponding self-help activity.

\section{Quality control}

\section{Standardize training for the researcher staff}

Four nurses with certification of Level II national psychological counsellors served as researcher staff in this study. A team of experts, including 1 clinical psychologist, 1 senior psychological consultant and 1 community geriatric specialist, was invited to join our study. The experts trained the researcher staff through demonstration teaching and simulated situational teaching. The training content included the form and content of lectures on mental health education, the organizational skills and processes of group activities, a psychological assessment technique, construction strategies of the optimal intervention path, methods of using the self-help intervention manual and choosing self-help intervention strategies.

\section{Monitoring the implementation of the P-oPSI}

During the intervention, the researchers communicated with the intervention group participants through weekly 


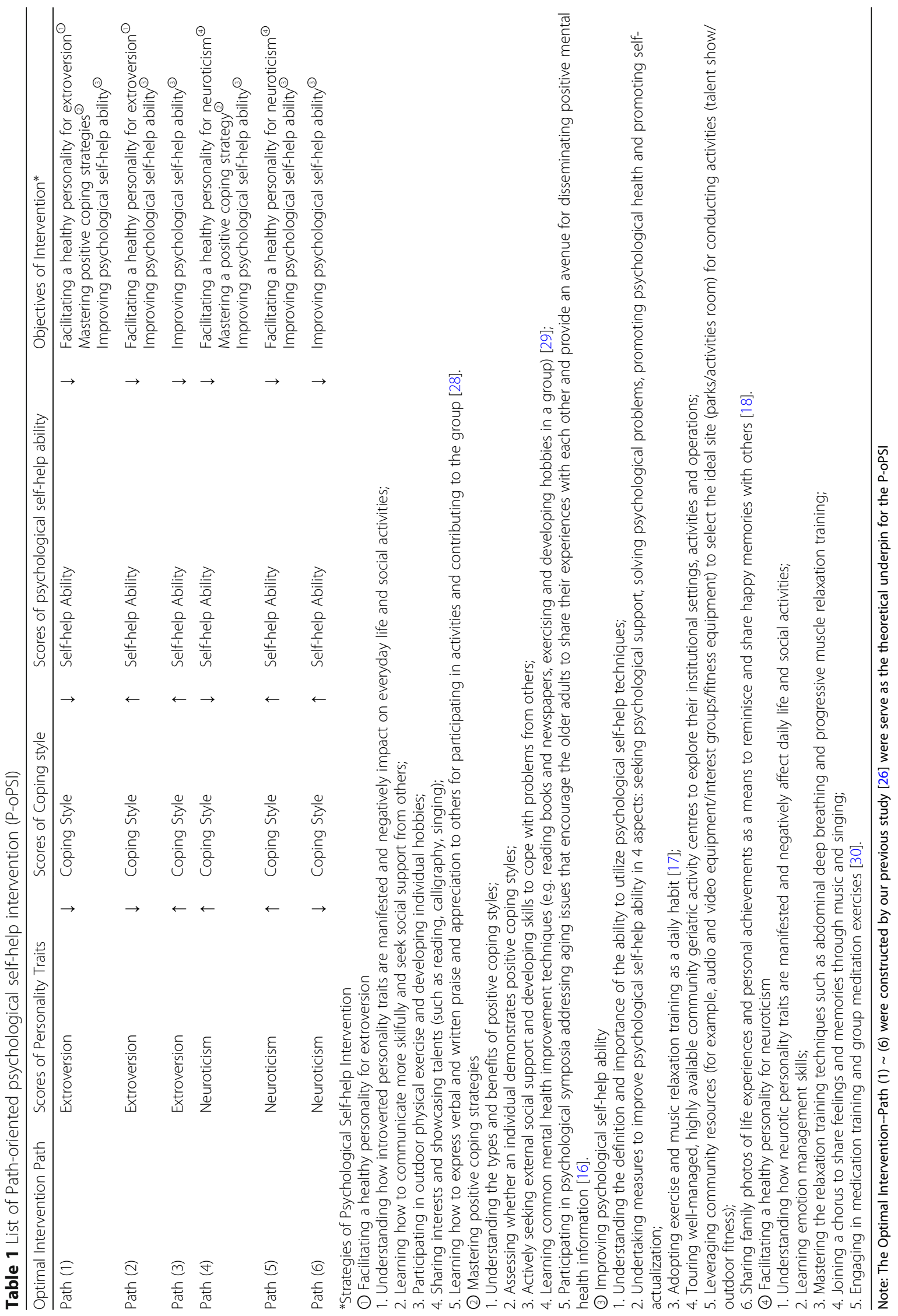


face-to face or telephone interviews. The research staff were trained to implement the intervention by assessing participants' mental health status and its changes so that they could tailor the intervention paths and strategies in a timely and flexible manner during the intervention.

\section{Outcomes and measuring instruments \\ Sociodemographic characteristics and personality traits}

We used an investigator-developed questionnaire that included gender, age, education level, occupation, marital status, monthly income, type of empty nest (absolutely empty-nest older adults, e.g., does not live with the children in the same city; or relatively empty-nest older adults, e.g., lives in the same city as the children, but does not live together with the children in the same household), method of payment for medical care and status of physical condition [31]. The personality trait in this study was measured by the Eysenck Personality Questionnaire-Revised Short Scale for Chinese (EPQRSC), which was originally designed by Eysenck et al. [32] and revised by Qian et al. [33]. EPQ-RSC consists of 48 items, forming 4 dimensions: extraversion (E), neuroticism $(\mathrm{N})$, psychoticism $(\mathrm{P})$ and a lie detector component inventory. Each of the items is scored as "yes $=1$ " or "no $=0$ ". In this study, the internal consistency coefficient of the four dimensions was 0.854, 0.756, 0.791 and 0.762 respectively. The average of Cronbach's $\alpha$ for EPQ-RSC was 0.83 .

\section{Primary outcome \\ Mental health status}

The Chinese Mental Health Scale (geriatric edition) was used to assess mental health status, which was constructed by Li et al. [34]. The scale consists of 68 items in 5 categories: self-cognition, emotional experience, adaptability, interpersonal communication and cognitive effectiveness. Each item has four response categories ranging from "non-conformity" (1 points) to "conformity" (4 points). The total score was the sum of 5 dimensions, ranging from 68 to 272 points. The Cronbach's $\alpha$ for the total scale and subscales were 0.95 and 0.75 0.88, respectively. In our study, the Cronbach's $\alpha$ of the total scale was 0.85 . In this study, the score of the scale was converted by using the percentile system as the weight, the critical point was six quartiles, and the total score $\leq 163$ was defined as the mental health substandard.

\section{Secondary outcomes \\ Coping style}

Coping style was assessed by the Simple Coping Style Questionnaire (SCSQ) in this study. This scale, compiled by Xie [35], is a self-rating scale with 20 items, which are divided into positive and negative coping styles.
There are four choices, including 'never use', 'use occasionally', 'use sometimes' and 'use frequently', and the corresponding score is $0,1,2$ and 3. The Cronbach's $\alpha$ coefficient of SCSQ was $0.78-0.89$. The Cronbach's $\alpha$ coefficient of this study was 0.88 .

\section{Psychological self-help ability}

The psychological self-help ability was assessed using the Empty-nest Older Adults Psychological Self-help Ability Scale compiled by Wang [36]. This scale includes 22 items in 4 dimensions: the ability to seek psychological support, the ability to solve mental health problem effectively, the ability to participate in mental health improvement activities and the ability to use selfrealization. The scale uses a 4-point Likert scale from 0 (never) to 3 (usually). This instrument's coefficient of internal consistency was 0.89 . The $\alpha$ coefficient was 0.81 in the present study.

\section{Adherence rate}

The adherence rate for all participants was calculated by the following formula: (Days to practice mental health self-help activities with reference to the manual of PoPSI / 30 days (duration of intervention) $\times 100 \%$.

\section{Procedures}

Baseline data, including information of sociodemographic and personality trait, mental health status, coping style and level of psychological self-help ability, were collected at community activity centres. At the end of one-month intervention, assessments were conducted, which included assessment of mental health status, coping style, level of psychological self-help ability and adherence rate. Same assessments were performed again at 3 months after intervention (3-month follow-up). Figure 2 presents the Consort flow diagram of the study design.

\section{Statistical analysis}

The data were managed and analysed using SPSS version 18.0. The $\chi^{2}$ test or Mann- Whitney $U$ test (for categorical variables) and $T$ test (for continuous variables) were applied to compare the sociodemographic and psychological variables of the two groups. A 2 (group) $\times 3$ (time) ANOVA was conducted to determine the effect of the group factors, time factors, and the interaction effects of 2 factors on the effectiveness of the P-oPSI. In the case of significant timexgroup interactions, a simple effect test was used to examine the difference among groups within each time point and the difference between the 3 time points within each group. Effect sizes at post-intervention were calculated with Cohen's d using the means and the pooled standard deviations of the measurements of the conditions (effect size of $0.56-$ 


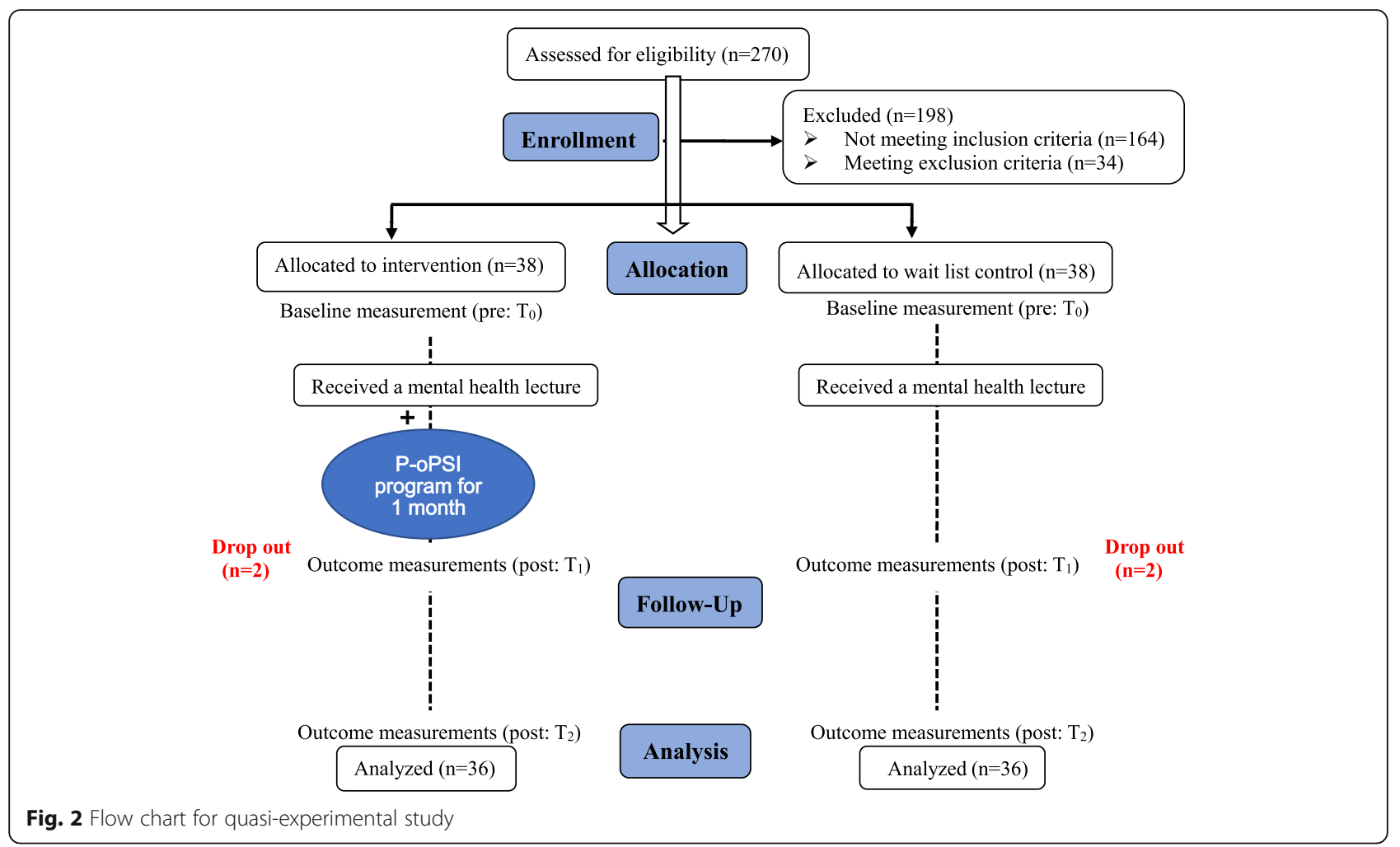

1.2 was considered large, $0.33-0.55$ as moderate, and less than 0.33 as small) [37].

\section{Results}

Two participants in the intervention group and 2 in the wait list control group withdrew from the study prior to the completion of the survey, due to a change in their health status, or their decision not to participate. Thus, a final total sample of 72 was included in the data analysis. The compliance rate of the intervention groups was $92.67 \%$.

\section{Descriptive features of empty-nest older adults}

The participants' mean age (in years) was $68.61( \pm 4.69)$; 39 (54.17\%) were female and $33(45.83 \%)$ were male. Other participant information is provided in Table 2 . There were no significant differences in the baseline sociodemographic and personality characteristics $(P>0.05)$ between the two groups of participants.

\section{Efficacy of the intervention}

A 2-way analysis of variance (depicted in Table 3) shows the mean values (standard deviations) of the study outcomes and their independent univariate $\mathrm{F}$ values between groups across three measurements. For all the outcome measures significant interactions effect were found $\left[\mathrm{F}_{(2,70)}=27.54-121.54\right.$, all $\left.p<0.001\right]$. It also demonstrates that the statistically significant main effect for the group factor was observed for positive coping style $\left[\mathrm{F}_{(1,35)}=4.99, p=0.032\right]$ and negative coping style $\left[\mathrm{F}_{(1,35)}=\right.$ $5.29, p=0.028]$, whereas the statistically significant main effect for the time factor were observed $\left[F_{(2,70)}=44.97\right.$ 126.78 , all $\mathrm{p}<0.001]$ for all the outcome measures. To determine the attribution of interaction effects, a simple effect test was conducted (See Table 4).

\section{Simple effect test on interaction effects for all outcomes}

As seen in Table 4, the group factor had no effects on the pre-test level $\left(\mathrm{F}_{(1,35)}=0.02-1.33\right.$, all $p>0.05$ and Cohen's $d<0.33$ ) for all the outcome measures, meaning that there were no significant differences at baseline on all the outcomes measures of the participants between two groups. On the post-test level after 1 month, the group factor had significant effects on all the outcome measures $\left(\mathrm{F}_{(1,35)}=7.07-8.85\right.$, all $p<0.01$ and Cohen's $d>$ 0.56), meaning that the amelioration of all outcomes were related to the effectiveness of the intervention(PoPSI) constructed in our study. After 3 months, the group factor also had also significant effects on all the outcome measures $\left(\mathrm{F}_{(1,35)}=10.42-16.13, p<0.01\right.$ and Cohen's $d>0.56$ ), meaning that our intervention persisted for 3 months. On all the outcome measures, high effect sizes were found for the intervention group compared with the wait list control group from postintervention to follow up. Comparisons were conducted separately for each group between the 3 time points [ $\mathrm{T}$ 
Table 2 Sociodemographic Characteristics of Participants in the Two Groups

\begin{tabular}{|c|c|c|c|c|}
\hline Sociodemographic and psychological characteristics & Invention Group $(n=36)$ & Wait List Control Group $(n=36)$ & value & $P$ value \\
\hline Age, mean (SD) & $68.31 \pm 5.06$ & $68.92 \pm 4.35$ & -0.550 & 0.584 \\
\hline Sex, n (\%) & & & 0.503 & 0.478 \\
\hline Male & $15(41.7)$ & $18(50.0)$ & & \\
\hline Female & $21(58.3)$ & $18(50.0)$ & & \\
\hline Education level, n (\%) & & & -1.200 & 0.230 \\
\hline Primary school and below & $10(27.8)$ & $8(22.2)$ & & \\
\hline Junior school & $18(50.0)$ & $14(38.9)$ & & \\
\hline High school & $6(16.6)$ & $12(33.3)$ & & \\
\hline College and above & $2(5.6)$ & $2(5.6)$ & & \\
\hline Marital status, n (\%) & & & 0.321 & 0.571 \\
\hline Married & $27(75.0)$ & $29(80.6)$ & & \\
\hline Single (divorced, widowed) & $9(25.0)$ & $7(19.4)$ & & \\
\hline Employment status, n (\%) & & & 1.042 & 0.594 \\
\hline Full-time employment & $10(27.8)$ & $14(38.9)$ & & \\
\hline Part-time employment & $17(47.2)$ & $15(41.7)$ & & \\
\hline Retired & $9(25.0)$ & $7(19.4)$ & & \\
\hline Monthly income, n (\%) & & & -0.538 & 0.590 \\
\hline $\operatorname{Low}(\leq 1000)$ & $10(27.8)$ & $12(33.3)$ & & \\
\hline Middle(1000 3000) & $20(55.5)$ & $19(52.8)$ & & \\
\hline $\operatorname{High}(\geq 3000)$ & $6(16.7)$ & $5(13.9)$ & & \\
\hline Physical condition, n (\%) & & & -0.813 & 0.416 \\
\hline Good & $15(41.7)$ & $18(50.0)$ & & \\
\hline Fair & $15(41.7)$ & $14(38.9)$ & & \\
\hline Poor & $6(16.6)$ & $4(11.1)$ & & \\
\hline Type of empty-nest, n (\%) & & & 1.185 & 0.276 \\
\hline Relatively empty-nest & $25(69.4)$ & $29(80.6)$ & & \\
\hline Absolutely empty-nest & $11(30.6)$ & $7(19.4)$ & & \\
\hline \multicolumn{5}{|l|}{ Score of personality trait } \\
\hline Extroversion, mean(SD) & $9.36 \pm 2.23$ & $9.75 \pm 1.95$ & -0.79 & 0.433 \\
\hline Neuroticism, mean(SD) & $9.69 \pm 1.89$ & $9.50 \pm 1.95$ & 0.43 & 0.669 \\
\hline Positive coping style,mean (SD) & $21.11 \pm 2.65$ & $21.03 \pm 2.64$ & 0.13 & 0.894 \\
\hline Negative coping style,mean (SD) & $12.36 \pm 3.80$ & $11.58 \pm 2.73$ & 0.99 & 0.323 \\
\hline psychological self-help ability, mean (SD) & $45.28 \pm 5.27$ & $45.00 \pm 4.71$ & 0.24 & 0.814 \\
\hline Mental-Health status,mean (SD) & $143.25 \pm 6.25$ & $144.81 \pm 4.82$ & -1.18 & 0.241 \\
\hline
\end{tabular}

WITHIN G (1), G (2)]. The results demonstrated that there were statistically significant differences $\left(\mathrm{F}_{(2,70)}=\right.$ $7.22-20.92, \mathrm{p}<0.01)$ in the intervention group before and after the intervention for all the outcome measures. Between-group effect sizes at post-intervention (Cohen's $d=-0.66-1.07$ ) and follow-up (Cohen's $d=-0.82-1.35$ ) were higher than that at baseline for all the outcome measures, which indicated that the level for all the outcome improved after 1 and 3 months of the intervention compared to the pre-test. Although all the outcome measures in the wait list control group showed a slight increase trend at 3 time points, there was no statistically significant differences before or after the intervention ( $F$ $(2,70)=0.21-0.78, P>0.05)$.

\section{Discussion}

\section{Summary of the findings}

To our knowledge, this is the first study that examined whether the various paths presented in Fig. 1 can be used to guide a self-help psychological intervention. The first aim of this study was to examine whether emptynest older adults, who participated in the P-oPSI, would 
Table 3 Impact of the Intervention on Outcome Measures at Three Time-points (Group $\times$ Time) test $(N=72)$

\begin{tabular}{|c|c|c|c|c|c|c|}
\hline \multirow[t]{2}{*}{ Outcome measures } & \multirow[t]{2}{*}{ Time $(\mathrm{T})$} & \multicolumn{2}{|l|}{ Group } & \multicolumn{2}{|c|}{ ANOVA: F } & \multirow[b]{2}{*}{ GroupxTime } \\
\hline & & Invention Group(G1) M \pm SD & Wait List Control Group(G2) $M \pm S D$ & Group & Time & \\
\hline \multicolumn{7}{|l|}{ Primary outcome } \\
\hline \multirow[t]{3}{*}{ Mental-Health status, mean (SD) } & TO & $143.46 \pm 6.22$ & $144.80 \pm 4.89$ & \multirow[t]{3}{*}{3.647} & \multirow[t]{3}{*}{$126.78^{* *}$} & \multirow[t]{3}{*}{$121.54^{* *}$} \\
\hline & $\mathrm{T} 1$ & $149.28 \pm 6.19$ & $145.57 \pm 4.88$ & & & \\
\hline & $\mathrm{T} 2$ & $150.69 \pm 5.59$ & $145.78 \pm 4.87$ & & & \\
\hline \multicolumn{7}{|l|}{ Secondary outcomes } \\
\hline \multirow[t]{3}{*}{ Positive coping style, mean (SD) } & TO & $21.11 \pm 2.65$ & $21.03 \pm 2.64$ & \multirow[t]{3}{*}{$4.99^{*}$} & \multirow[t]{3}{*}{$44.967^{* *}$} & \multirow[t]{3}{*}{$27.537^{* *}$} \\
\hline & $\mathrm{T} 1$ & $23.64 \pm 2.53$ & $21.83 \pm 3.10$ & & & \\
\hline & $\mathrm{T} 2$ & $23.78 \pm 2.51$ & $21.61 \pm 3.01$ & & & \\
\hline \multirow[t]{3}{*}{ Negative coping style, mean (SD) } & TO & $12.36 \pm 3.80$ & $11.58 \pm 2.73$ & \multirow[t]{3}{*}{$5.29^{*}$} & \multirow[t]{3}{*}{$125.14^{* *}$} & \multirow[t]{3}{*}{$115.51^{* *}$} \\
\hline & $\mathrm{T} 1$ & $8.67 \pm 3.05$ & $10.89 \pm 2.91$ & & & \\
\hline & $\mathrm{T} 2$ & $8.03 \pm 2.47$ & $11.03 \pm 2.76$ & & & \\
\hline \multirow{3}{*}{$\begin{array}{l}\text { psychological self-help ability, mean } \\
\text { (SD) }\end{array}$} & TO & $45.28 \pm 5.27$ & $45.00 \pm 4.71$ & \multirow[t]{3}{*}{3.94} & \multirow[t]{3}{*}{$93.87^{* *}$} & \multirow[t]{3}{*}{$49.49^{* *}$} \\
\hline & T1 & $48.69 \pm 5.00$ & $45.61 \pm 4.39$ & & & \\
\hline & $\mathrm{T} 2$ & $49.44 \pm 4.93$ & $45.69 \pm 4.59$ & & & \\
\hline
\end{tabular}

Notes: T0, baseline; T1, post-intervention at 1 month (directly after the intervention); T2, 3-month follow-up (4 months after baseline); ANOVA, Analysis of variance; ${ }^{*} P<0.05 ;{ }^{* *} P<0.01$

perform better on mental health outcomes than the wait list control group (Hypothesis 1). The second aim was to test whether P-oPSI would be superior to a groupbased mental health education in promoting mental health of empty-nest older adults (Hypothesis 2).

The participants were highly interested in the study and the compliance rate of P-oPSI was high. The results supported Hypothesis 1, which show that the implementation of P-oPSI was effective on mental health status of the participants. Moreover, compared to the mental health education for the wait list control group, P-oPSI resulted in overall improvements in coping styles, the psychological self-help ability and the mental health status with large effect sizes (supportive of Hypothesis 2). In addition, the P-oPSI had a last effect 3 months after the intervention.

\section{Comparison with other studies Primary outcome}

In this study, participants' mental health status significantly improved in the intervention group but only increased slightly in the wait list control group. The results of this study are consistent with other studies which showed that psychological self-help interventions

Table 4 Results of Simple Effects of Interaction Effects on All Outcomes

\begin{tabular}{|c|c|c|c|c|c|c|c|c|}
\hline \multirow{2}{*}{$\begin{array}{l}\text { Source of } \\
\text { Variation }\end{array}$} & \multicolumn{2}{|c|}{ Mental Health Status } & \multicolumn{2}{|c|}{ Positive coping style } & \multicolumn{2}{|c|}{ Negative coping style } & \multicolumn{2}{|c|}{ psychological self-help ability } \\
\hline & $F$ & Cohen's d & $F$ & Cohen's d & $F$ & Cohen's d & $F$ & Cohen's d \\
\hline G WITHIN TO & 1.33 & -0.28 & 0.02 & 0.03 & 1.08 & 0.24 & 0.06 & 0.06 \\
\hline G WITHIN T1 & $7.59^{* *}$ & 0.67 & $7.24^{* *}$ & 0.64 & $8.85^{* *}$ & -0.745 & $7.07^{* *}$ & 0.65 \\
\hline G WITHIN T2 & $13.24^{* *}$ & 0.94 & $10.42^{* *}$ & 0.78 & $16.13^{* *}$ & -1.15 & $10.45^{* *}$ & 0.79 \\
\hline T WITHIN G1 & $18.12^{* *}$ & & $10.14^{* *}$ & & $20.92^{* *}$ & & $7.22^{* *}$ & \\
\hline G1 (T0 v. T1) & & -0.97 & & -0.98 & & 1.07 & & -0.66 \\
\hline G1 (T0 v. T2) & & -1.26 & & -1.03 & & 1.35 & & -0.82 \\
\hline G1 (T1 v. T2) & & -0.24 & & -0.06 & & 0.23 & & -0.15 \\
\hline T WITHIN G2 & 0.30 & & 0.78 & & 0.52 & & 0.21 & \\
\hline G2 (T0 v. T1) & & -0.16 & & -0.28 & & 0.25 & & -0.13 \\
\hline G2 (T0 v. T2) & & -0.20 & & -0.21 & & 0.20 & & -0.15 \\
\hline G2 (T1 v. T2) & & -0.05 & & 0.07 & & -0.05 & & -0.02 \\
\hline
\end{tabular}

Notes:G WITHIN T1: The simple effect of G at T1 level (the comparative results on levels of baseline in intervention and wait list control groups); G WITHIN T2: the comparative results of the 2 groups after one-month intervention; G WITHIN T3: the comparative results of the 2 groups after three-month intervention; T WITHIN G1: the comparative results of the intervention group at baseline, after one-month intervention and after three- month intervention; T WITHIN G2: the comparative results of the wait list control group at baseline, after one-month intervention and after three-month intervention; ${ }^{*} P<0.05$; ${ }^{* *} P<0.01$ 
can be effective in improving the elders' psychological well-being [38, 39], reflected by the similar effect sizes achieved in our study, compared with the overall effect sizes reported in two meta-analyses [39, 40]. This may particially due to our study's tailored intervention design that effectively improved the participants' mental health status.

\section{Secondary outcomes}

$\mathrm{P}$-oPSI is based on cognitive behavioral principles and focusses on two major areas, the enhancement of positive coping responses and psychological self-help ability. The mediating effect of coping style between personality and mental health has been confirmed in the "standard model" established by previous studies [40, 41]. That is, based on positive coping style adjustment, personality traits can have a long-term positive impact on the mental health of individuals. The manual of self-help intervention provides a variety of practical and effective coping skills that study participants can utilize depending on to their situation. Through the P-oPSI, the participants will understand their personality traits and begin to seek advantages and reduce distress when managing life events.

In this study, the significant improvement in the Simple Coping Style Questionnaire (SCSQ) scores was found at 1-month post intervention compared with the wait list control group. This improvement is long-lasting (over 3 months, Cohen's $d=0.78$ ), and almost identical to those found in a narrative review of psychological self-help intervention [42], which included 20 qualitative studies which showed that people used a wide range of self-help strategies in their everyday struggle to cope with their mental health symptoms.

The findings of this study also indicated that the psychological self-help ability score of the empty-nest older adults in the intervention group increased steadily over the 3-month follow-up (Cohen's $d=0.79$ ), similar to findings which indicate that self-help intervention will significantly affect the planning and implementing of healthrelated behaviors $[43,44]$. Our intervention approach is easibly acceptable to the particpants because it fits into the Chinese culture; instead of seeking professional services, individuals would like to cope with mental health issues with the help of their family and relatives. Previous studies have shown that engaging in self-help enhances a sense of control, self-efficacy, self-reliance, and autonomy $[45,46]$. The strategies of psychological self-help used in this study were to increase health promoting behavior and to develop behavioral changes in the prevention of emptynest older adults' mental disorder. We found that during the follow-up, the participants in the intervention group often talked about some positive physical and psychological changes resulting from P-oPSI, as well as some next steps or actions about promoting mental health. Our study suggests that planning a health-related behavior could lead to improved self-efficacy or psychological selfhelp ability [47].

Study recruitment, adherence rates, and patient experience results indicate that P-oPSI is likely safe and acceptable. The adherence rate of the intervention groups in this study was $92.67 \%$; whereas, the attrition rate was very low $(5.2 \%)$, in contrast to other similar intervention studies $[43,48]$. This high adherence rate might be attributed by an individual's optimal intervention path, practising of self-care behaviours, and easy to understand reading materials. It could also be attributed to our team's effort in maintaing regular contacts and reminding of the participants to stay in the P-oPSI.

As we expected, the findings showed that changes in coping style and the psychological self-help ability mediated improvements in participants' mental health status. Older adults who accepted the intervention of P-oPSI exhibited a greater reduction in negative strategies and a significant increase in psychological self-help behaviours. In order to promoting mental helath, P-oPSI can be conducted and managed by older adults themselves; it might be an effective, cost-efficient and readily available alternative for empty-nest older adults without severe psychosis in the context of lack access to professional psychological counselling in a primary community health care center in China. However, it is worth noting that it is essential to seek help from professional healthcare providers when individuals suffer from major mental health problems.

\section{Limitations and future research directions}

Although findings from this study supported the effects of P-oPSI for facilitating empty-nest older adults' mental health, limitations need be acknowledged. First, this was a quasi-experimental study. The limitations of this design include its small sample size, the lack of blinding, probable social desirability bias, selection bias, and limited external validity of the findings. Future studies are needed to address these methodological weaknesses and investigate the applicability and effects of P-oPSI using larger and more diverse samples. Second, this study targets a particular population, the empty-nest older adults. Such population with poor status in mental health do not live with their children, which might limit the generalizability of our findings to genearl populations of older adults with psychological problems. Third, P-oPSI only considers coping styles and psychological self-help ability as mediating mechanisms, leaving out other potential mechanisms such as psychosocial resources (e.g., resilience and social support), which may also serve as mediating variables. Fourth, we did not follow-up the participants beyond 3 months. Therefore, the long-term impact of P-oPSI are unclear. 


\section{Conclusions}

Currently, there is inadequate social and health insurance for older adults in China, coupled with scare resources and a significant disparity in its distributon across the regions (e.g., urban vs. rural areas, east vs. west region). Therefore, "psychological self-help" will play a crucial role in the mental health care of older adults. The P-oPSI in the community setting can help promote the psychological potential of the empty-nest older adults and can be provided at relatively low costs, which is critical to disseminate in the nursing practice of community mental health promotion for the empty-nest older adults.

\section{Abbreviations}

P-oPSI: Path-oriented Psychological Self-help Intervention; SEM: Structural Equation Modelling

\section{Acknowledgements}

We thank the community workers JY Cao, JH Zheng for their important work on the P-oPSI. We also thank Shahrzad Siamdoust from New York University for editing assistance for this manuscript.

\section{Authors' contributions}

BW and LNW conceived the study and participated in its design. LNW, MW and $\mathrm{HS}$ participated in coordinating the study and the data collection. LNW and MW performed the statistical analysis. LNW, HT and HWY drafted the manuscript, HT and BW revised the manuscript. All authors read and approved the final manuscript.

\section{Funding}

This work was supported by the National Natural Science Foundation(NO.71704053); China Scholarship Council (NO.201908330251); and Zhejiang Province Natural Science Foundation (NO.LQ17G030002). The funding bodies did not participate neither in the design of the study nor in the data analysis and manuscript elaboration.

\section{Availability of data and materials}

The datasets used and/or analysed during the current study are available from the corresponding author on reasonable request.

\section{Ethics approval and consent to participate}

This study protocol was reviewed by the Chifeng University's Institutional Review Board, Clinical Trial Committee in addition to the University Medical Ethics Committee. This study was conducted in accordance with the ethical principles of the Declaration of Helsinki. All empty-nest older adults who met the study's inclusion and exclusion criteria were informed of the study's objectives, procedures, psychological benefits, and potential risks. Oral and written consent was obtained from the participants, and all information regarding them was kept strictly confidential.

\section{Consent for publication}

Not applicable.

\section{Competing interests}

The authors declare that they have no competing interests.

\section{Author details}

'School of Medicine, Huzhou University, Huzhou Central Hospital, Huzhou 313000, Zhejiang, China. ${ }^{2}$ AdventHealth Whole-Person Research, Orlando, FL 32804, USA. ${ }^{3}$ School of Nursing, Binzhou Polytechnic, Binzhou 256600, Shandong, China. ${ }^{4}$ School of Nursing, Harbin Medical University, DaQing Campus, Daqing 163319, China. ${ }^{5}$ Rory Meyers College of Nursing, New York University, 433 First Avenue, New York, NY 10010, USA.
Received: 9 August 2019 Accepted: 17 October 2019

Published online: 21 November 2019

\section{References}

1. Bouchard G. How do parents react when their children leave home? An integrative review. J Adult Dev. 2014;21(2):69-79 https://doi.org/10.1007/ s10804-013-9180-8.

2. Thapa DK, Visentin D, Kornhaber R, Cleary M. Migration of adult children and mental health of older parents 'left behind': an integrative review. PLoS One. 2018;13(10):e0205665 https://doi.org/10.1371/journal.pone.0205665.

3. Bouchard G. A dyadic examination of marital quality at the emptynestphase. Int J Aging Hum Dev. 2018;86(1):34-50 https://doi.org/10.1177/ 0091415017691285.

4. Wu ZQ, Sun L, Sun YH, Zhang XJ, Tao FB, Cui GH. Correlation between Ioneliness and social relationship among empty nest elderly in Anhui rural area, China. Aging Ment health. 2010;14(1): 108-12. https://doi.org/10.1080/ 13607860903228796

5. Wu YS. China report of the development on aging cause. Beijing: Social Sciences Academic Press; 2013.

6. Li DM, Chen TY, Li GY. The problem of mental health in the elderly in empty-nest family. Chin J Gerontol. 2003;23(7):405-7.

7. Logan JR, Bian F, Bian Y. Tradition and change in the urban Chinese family: the case of living arrangements. Soc Forces. 1998;76(3):851-82 https://scihub.se/10.2307/3005696.

8. Silverstone $\mathrm{B}$, Kandel $\mathrm{HH}$. You and your aging parent: a family guide to emotional, social, health, and financial problems. Educ Gerontol. 2012;38: 146-7 https://doi.org/10.1080/03601277.2010.515915.

9. Cheng $P$, Jin $Y$, Sun $H$, Tang Z, Zhang C, Chen YJ, Zhang Q, Zhang QH, Huang F. Disparities in prevalence and risk indicators of loneliness between rural empty nest and non-empty nest older adults in Chizhou, China. Geriatr Gerontol Int. 2015;15(3):356-64 https://sci-hub.se/10.1111/ggi.12277.

10. Xin F, Liu XF, Yang G, Li XF, Li GZ, Wang WB, Chen M. Prevalence of depression in Chinese empty-nest elderly: a meta-analysis. Chinese Journal of Health Statistics. 2014;31(2):278-81.

11. Eloranta S, Arve S, Isoaho H, Lehtonen A, Viitanen M. Loneliness of older people aged 70: a comparison of two Finnish cohorts born 20 years apart. Arch Gerontol Geriatr. 2015;61(2):254-60 https://doi.org/10.1016/j.archger. 2015.06.004

12. Liu LJ, Guo Q. Loneliness and health-related quality of life for the empty nest elderly in the rural area of a mountainous county in China. Qual Life Res. 2007:16(8):1275-80 https://doi.org/10.1007/s11136-007-9250-0.

13. Duane F, Brasher K, Koch S. Living alone with dementia. Dementia. 2013; 12(1):123-36 https://doi.org/10.1177/1471301211420331.

14. Valtorta NK, Kanaan M, Gilbody S, Hanratty B. Loneliness, social isolation and social relationships: what are we measuring? A novel framework for classifying and comparing tools. BMJ Open 2016; 6(4): e010799. https://doi. org/10.1136/bmjopen-2015-010799.

15. Rifel J, Svab I, Selic P, Pavlic DR, Nazareth I, Car J. Association of common mental disorders and quality of life with the frequency of attendance in Slovenian family medicine practices: longitudinal study. PLoS One 2013; 8(1): e54241. https://doi.org/10.1371/journal.pone.0054241.

16. Joo JH, Hwang S, Abu H, Gallo JJ. An innovative model of depression care delivery: peer mentors in collaboration with a mental health professional to relieve depression in older adults. Am J Geriatr Psychiatry. 2016;24(5):407-16 https://doi.org/10.1016/j.jagp.2016.02.002.

17. Sánchez A, Maseda A, Marante-Moar MP, de Labra C, Lorenzo-López L, Millán-Calenti JC. Comparing the effects of multisensory stimulation and individualized music sessions on elderly people with severe dementia: a randomized controlled trial. J Alzheimers Dis. 2016;52(1):303-15 https://doi. org/10.3233/JAD-151150.

18. Sok SR. Effects of individual reminiscence therapy for older women living alone. Int Nurs Rev 2015; 62(4):517-524.https://doi.org/10.111/inr.12190.

19. Norcross JC, Bike DH, Evans KL. The therapist's therapist: a replication and extension 20 years later. Psychotherapy (Chic). 2009;46(1):32-41 https://doi. org/10.1037/a0015140.

20. Hirase T, Kataoka H, Nakano J, Inokuchi S, Sakamoto J, Okita M. Effects of a psychosocial intervention programme combined with exercise in community-dwelling older adults with chronic pain: a randomized controlled trial. Eur J Pain. 2018;22(3):592-600 https://doi.org/10.1002/ ejp.1149. 
21. Roder V, Mueller DR, Schmidt SJ. Effectiveness of integrated psychological therapy (IPT) for schizophrenia patients: a research update. Schizophr Bull. 2011; 37( Suppl 2):71-9. https://doi.org/10.1037/a0015140.

22. Fisher AJ, Boswell JF. Enhancing the personalization of psychotherapy with dynamic assessment and modeling assessment 2016; 23(4): 496-506. https://doi.org/10.1177/1073191116638735.

23. Niclasen J, Lund L, Obel C, Larsen L. Mental health interventions among older adults: a systematic review. Scand J Public Health. 2019;47(2):240-50 https://doi.org/10.1177/1403494818773530.

24. Fisher AJ, Bosley HG. Personalized assessment and treatment of depression. Curr Opin Psychol. 2015;4:67-74 https://doi.org/10.1016/j.copsyc.2015.03.03.

25. Briley DA, Tucker-Drob EM. Genetic and environmental continuity in personality development: a meta-analysis. Psychol Bull. 2014;140(5):1303-31 https://doi.org/10.1037/a0037091.

26. Wang LN, Cao JY, Su H, Zhou YQ. Mediating Effect of Coping Styles and self-help capabilities on the factors affecting the mental health of urban empty nesters chinese general practice 2017; 20(16): 2012-2018.

27. Kadel RP, Kip KE. 2012. A SAS macro to compute effect size (Cohen's d) and its confidence interval from raw survey data (available at: http://analytics. ncsu.edu/sesug/2012/SD-06.pdf; accessed 30 Jul 2014).

28. Alison K, Ann M. Using a gratitude intervention to enhance well-being in older adults. J Happiness Stud. 2015;16(4):947-64 https://doi.org/10.1007/ s10902-014-9542-3.

29. SMA El-K, Al-Jiffri OH. Aerobic exercise improves quality of life, psychological well-being and systemic inflammation in subjects with Alzheimer's disease. Afr Health Sci. 2016;16(4):1045-55 https://doi.org/10.4314/ahs.v16i4.22.

30. Carter KS, Carter IR. Breath-based meditation: a mechanism to restore thephysiological and cognitive reserves for optimal human performance. World J Clin Cases. 2016;4(4):99-102 https://doi.org/10.12998/wjcc.v4.i4.99.

31. Li DM, Chen TY. The mental health status and the influencing factors of the elderly. The Chinese elderly Society 2006 Elderly Academic Summit Forum Proceedings 2006.

32. Eysenck SBG, Eysenck HJ, Barrett P. A revised version of the psychoticism scale. Personal Individ Differ. 1985;6(1):21-9 https://doi.org/10.1016/01918869(85)90026-1.

33. Qian MY, Wu GC, Zhu RC. A revised version of Eysenck personality questionnaire short form scale Chinese version (EPQ-RSC). J Psychol. 2000; 32(6):317-23.

34. Li J, Wu ZY, Han BX. Development of mental health inventory for the elderly(urban version). Chin Ment Health J. 2009;23(7):656-60.

35. Xie YN. A preliminary study on the reliability and validity of the simple coping style questionnaire. Chin J Clinic Psychol. 1998;6:114-5.

36. Wang LN, Su H, Li SS, Yao JL, Zhou YQ. Development of empty-nest elderly mental health self-help ability scale and testing of its reliability and validity. Chinese General Practice. 2016;19:4379-84.

37. Lipsey MW, Wilson DB. The efficacy of psychological, educational, and behavioural treatment: confirmation from meta-analysis. Am Psychol. 1993; 48(12):1181-209 https://doi.org/10.1037/0003-066x.48.12.1181.

38. Sommers-Spijkerman MPJ, Trompetter H, Schreurs KMG, Bohlmeijer ET Compassion-focused therapy as guided self-help for enhancing public mental health: a randomized controlled trial. J Consult Clin Psychol. 2018; 86(2):101-15 https://doi.org/10.1037/ccp0000268

39. Den Boer PCAM, Wiersma D, Van Den Bosch RJ. Why is self-help neglected in the treatment of emotional disorders? A meta-analysis Psychol Med. 2004:34(6):959-71 https://doi.org/10.1017/S003329170300179X.

40. Su H, Cao JQ, Zhou YQ, Wang LN, Xing L. The mediating effect of coping style on personality and mental health among elderly Chinese emptynester: a cross-sectional study. Arch Gerontol Geriatr. 2018;75:197-201 https://doi.org/10.1016/j.archger.2018.01.004.

41. Zhang DH, Wu YJ, Pan X. Chinese personality traits and mental health: mediating effect of coping style. Frontiers in psychological and behavioral. Science. 2013;2(4):68-72.

42. Lucock M, Gillard S, Adams K, Simons L, White R, Edwards C. Self-care in mental health services: a narrative review. Health Soc Care Community. 2011;19(6):602-16 https://doi.org/10.1111/j.1365-2524.2011.01014.x.

43. Garnefski N, Kraaij V, Benoist M, Bout Z, Karels E, Smit A. Effect of a cognitive behavioral self-help intervention on depression, anxiety, and coping selfefficacy in people with rheumatic disease. Arthritis Care Res (Hoboken). 2013;65(7):1077-84 https://sci-hub.se/10.1002/acr.21936.

44. Furuya RK, Arantes EC, Dessotte CAM, Ciol MA, Hoffman JM, André S, Dantas RAS, Rossi LA. A randomized controlled trial of an educational programme to improve self-care in Brazilian patients following percutaneous coronary intervention. J Adv Nurs. 2015;71(4):895-908 https:// sci-hub.se/10.1111/jan.12568.

45. Lambert SD, Beatty L, McElduff $P$, Levesque JV, Lawsin C, Jacobsen P, Turner J, Girgis A. A systematic review and meta-analysis of written selfadministered psychosocial interventions among adults with a physical illness. Patient Educ Couns. 2017;100(12):2200-17 https://dx.dio.org/dio:10.1 016/j.pec.2017.06.039.

46. Schulman-Green D, Jeon S. Managing Cancer care: a psycho-educational intervention to improve knowledge of care options and breast cancer selfmanagement. Psychooncology. 2017;26(2):173-81 https://doi.org/10.1002/ pon.4013.

47. Keller J, Gellert P, Knoll N, Schneider M, Ernsting A. Self-efficacy and planning as predictors of physical activity in the context of workplace health promotion. Appl Psychol Health Well Being. 2016;8(3):301-21 https:// doi.org/10.1111/aphw.12073.

48. Sugiyama T, Steers WN, Wenger NS, Duru OK, Mangione CM. Effect of a community-based diabetes self-management empowerment program on mental health-related quality of life: a causal mediation analysis from a randomized controlled trial. BMC Health Serv Res. 2015;15(1):115 https://doi. org/10.1186/s12913-015-0779-2.

49. Bower PJ, Richards D, Lovell K. The clinical and cost-effectiveness of selfhelp treatments for anxiety and depressive disorders in primary care: a systematic review. Br J Gen Pract. 2001;51(471):838-45 https://doi.org/10. 3109/07853890109002100.

\section{Publisher's Note}

Springer Nature remains neutral with regard to jurisdictional claims in published maps and institutional affiliations.
Ready to submit your research? Choose BMC and benefit from:

- fast, convenient online submission

- thorough peer review by experienced researchers in your field

- rapid publication on acceptance

- support for research data, including large and complex data types

- gold Open Access which fosters wider collaboration and increased citations

- maximum visibility for your research: over $100 \mathrm{M}$ website views per year

At $\mathrm{BMC}$, research is always in progress.

Learn more biomedcentral.com/submissions 